\title{
A study of the thermal degradation of glass fibre sizings at composite processing temperatures
}

James L. Thomason, Ulf Nagel, Liu Yang and David Bryce

University of Strathclyde, Department of Mechanical and Aerospace Engineering, 75

Montrose Street, Glasgow G1 1XJ, United Kingdom. 


\title{
A study of the thermal degradation of glass fibre sizings at
}

\section{composite processing temperatures}

James L. Thomason, Ulf Nagel, Liu Yang and David Bryce

University of Strathclyde, Department of Mechanical and Aerospace Engineering, 75

Montrose Street, Glasgow G1 1XJ, United Kingdom.

\begin{abstract}
Although not fully understood, it is well recognized that optimal working of glass fibre sizings is necessary to maximize the performance of glass fibre reinforced polymer composites. It is important that the organic components in such sizings continue to function after exposure to the high temperatures often experienced during composite processing. This study presents the results on the thermal stability of polypropylene and epoxy compatible glass fibre sizings obtained using TGA, microbond adhesion measurement and composite mechanical testing. Test results indicate that the performance of commercial polypropylene compatible glass fibre sizings can be significantly compromised by thermo-oxidative degradation at normal composite processing temperatures. A significant reduction in composite performance is directly related to a loss of fibre-matrix adhesion caused by thermal degradation of some of the principal sizing components.
\end{abstract}

Keywords: A Glass fibres, B Fibre/matrix bond, B Mechanical properties, D Thermal analysis, X Sizing, 


\section{Introduction}

The formulation and application of sizing to reinforcement fibres is a critical component to the cost-effective production of glass fibre products and their processibility into composite materials with optimized short and long term performance. Despite the importance of glass fibre sizes to all virtually all aspects of the processing and performance of glass reinforced polymer (GRP) composites, size and sizing remains a "black box" technology in composites since glass fibre producers are very reticent to reveal much information about the complex formulations they use. Consequently openly available descriptions of sizes tend to be highly generic in nature. Typically the reader will be told that sizes are dilute water based emulsions or dispersions containing a complex mixture of components. These will often be described more by their generic function rather than by their exact chemical formulae. The primary components are the film former and the coupling agent [1-3]. The film former is designed to protect and lubricate the fibres and hold them together prior to composite processing, yet also to promote their separation when in contact with resin, ensuring wetout of all the filaments. The coupling agent, almost always an alkoxysilane compound, is often said to serve primarily to bond the fibre to the matrix resin. Beyond these two components, sizes also may include additional lubricating agents, antistatic agents and surfactants.

Optimization of the stress transfer capability of the fibre-matrix interphase region is critical to achieving the required performance level in composite materials. The ability to transfer stress across the fibre-matrix interphase in composites is often reduced to a discussion of 'adhesion'. This is a simple term to describe a combination of complex phenomena and there is still significant debate as to its definition and measurability.

Due to its initial location on the fibre surface, sizing is also a critical component in the 
formation and properties of the fibre-matrix interphase [1-7]. Another very important function of glass fibre sizes is their role in establishing and maintaining a high level of fibre strength in glass fibre products $[1,2,8,9]$. This aspect of glass fibre sizes has been highlighted recently due to an increase in research of the possibilities for recycling end of life composites. A number of authors have reported on the loss of strength and surface functionality when glass fibres are exposed to elevated temperatures. It has been suggested [8-12] these phenomena are related to the loss of functionality of the fibre sizing and fundamental changes in the flaw distribution density and severity on the fibre surface. Many composite processes require exposure of fibres and polymers to elevated temperature, in particular thermoplastic composite processing routinely requires processing temperatures above $250{ }^{\circ} \mathrm{C}$. At these high temperatures the thermal stability of organic materials such as polymers and sizing components starts to become a concern $[12,13]$. Thermal degradation of two epoxy resin based sizings on carbon fibres has been studied using thermogravimetric analysis [14]. One sizing was stable up to about $300^{\circ} \mathrm{C}$ and then degraded in a single step with a peak maximum around $400^{\circ} \mathrm{C}$. A second reactive sizing showed a step degradation pattern with the initial degradation starting already below $200^{\circ} \mathrm{C}$ and with peaks at $250^{\circ} \mathrm{C}$ and $420^{\circ} \mathrm{C}$. The thermo-oxidative stability of sizing on commercially available fibres chopped carbon fibres has also been investigated using XPS [15]. Results showed a rapid thermo-oxidative altering of the initial surface functionalities at both $190^{\circ} \mathrm{C}$ and $240^{\circ} \mathrm{C}$. Of particular interest was a result which showed that oxidative degradation of the sizing can also take place during standard PP composite processing. In this paper we report results of an investigation of glass fibre sizing thermal stability at temperatures in the $200-500{ }^{\circ} \mathrm{C}$ range and further report on the effects of sizing degradation on interfacial adhesion and composite 
performance.

\section{Experimental}

\subsection{Materials}

The glass fibres used in this study are listed in Table 1. E-glass fibres from three manufacturers were used and these included boron-free and boron containing E-glass formulations. The composite samples were produced using fibre B1 which is a commercial boron-free E-glass $4 \mathrm{~mm}$ chopped glass product. The fibres were received as chopped bundles with a polypropylene compatible sizing. The other fibres used in the sizing degradation study were all continuous single end rovings. Commercial PP compatible boron containing E-glass rovings designed for long fibre thermoplastic processing were obtained from PPG Fibre Glass (now NEG). Boron-free E-glass fibres OW and OA were produced on a 2000 hole pilot bushing by Owens Corning. No sizing was applied to the water finished fibres (OW) which had only been water sprayed using the normal cooling sprays under the bushing; these samples are referred to as water sized, unsized or bare. The silane sized fibres (OA) were coated with a normal rotating cylinder sizing applicator containing a $1 \%$ aminopropyltriethoxysilane (APS) hydrolysed solution in distilled water. All fibre packages were subsequently dried at 105 ${ }^{\circ} \mathrm{C}$ for 24 hours

The procedure from previous glass fibre studies was followed to perform the thermal preconditioning of the glass fibres [10]. A Carbolite CWF 12/13 furnace was used to thermally precondition the glass fibres in air. The fibres were placed in a preheated furnace and treated at different temperatures. After $25 \mathrm{~min}$ the fibres were allowed to cool down at ambient temperature outside of the furnace. A Netszch STA 449 F1 
thermal analyser was used to thermally precondition the glass fibres at different temperatures in a nitrogen atmosphere. The temperature profile consisted of a dynamic section with a heating rate of $25{ }^{\circ} \mathrm{C} / \mathrm{min}$ and an isothermal section of $25 \mathrm{~min}$ at the desired temperature in the range $200^{\circ} \mathrm{C}$ to $500^{\circ} \mathrm{C}$. After the isothermal section the fibres were cooled down with a cooling rate of $25^{\circ} \mathrm{C} / \mathrm{min}$.

\subsection{Thermal Analysis}

Thermal gravimetric analysis (TGA) temperature scans with a heating rate of 10 ${ }^{\circ} \mathrm{C} / \mathrm{min}$ were performed using a Netzsch STA 449 F1 Jupiter thermogravimetric analyser. The weight loss of glass fibres with different sizings, PP, MAPP and dried APS film was recorded as a function of the temperature in air and a nitrogen atmosphere. The weight of the sizings on the glass fibre samples is generally relatively small which can lead to scatter of the TGA signal. However, the large volume of the beaker of the Netzsch equipment allowed a large sample size of $250 \mathrm{mg}$.

\subsection{Microbond Technique}

The procedure for preparation and testing of microbond samples has been described in detail [16-18]. The PP droplets were formed at $220{ }^{\circ} \mathrm{C}$ in an $\mathrm{OV}-11$ vacuum oven that was purged with nitrogen. The epoxy resin systems used were Araldite ${ }^{\circledR} 506$ and $\mathrm{DER}^{\mathrm{TM}} 332$ both reacted with triethylenetetramine, technical grade $60 \%$, (TETA) curing agent. Both epoxy resins are bisphenol-A diglycidyl ether-based and the 506 resin also contains a reactive diluent. The epoxy resin and curing agent were mixed to the stoichiometric ratio and degassed for 10 minutes. A length of steel wire was used to apply resin to the fibres in order to form axisymmetric micro-droplets suitable for testing. The samples were then cured at $60^{\circ} \mathrm{C}$ for 1 hour followed by $120^{\circ} \mathrm{C}$ for 2 hours. 
A Nikon Epiphot inverted optical microscope was used to screen the microbond samples and measured the fibre diameter (D) and embedded length $\left(\mathrm{L}_{\mathrm{e}}\right)$. Only samples with symmetric droplets were tested. An Instron 3342 universal testing machine equipped with a $10 \mathrm{~N}$ load cell was used to apply load to the microbond samples. The test speed was set to $0.1 \mathrm{~mm} / \mathrm{min}$ and all tests were performed at room temperature (22 $\pm 2{ }^{\circ} \mathrm{C}$ ). Instron Bluehill 2 software recorded the load as a function of the displacement. The test was stopped after the load reached a maximum value $\left(\mathrm{F}_{\max }\right)$ and dropped to a constant minimum value. The $\mathrm{F}_{\max }$ value was used, along with the measured fibre diameter and embedded length, to estimate the apparent IFSS, $\tau_{\text {app }}$, using Equation 1.

$$
\tau_{a p p}=\frac{F_{\max }}{\pi D_{f} L_{e}}
$$

\subsection{Composite Preparation and Mechanical Testing}

A Betol BC25 extruder was used to compound SABIC® PP 579 S polypropylene (PP) pellets with the 30\% wt. of B1 chopped glass fibres. $1 \%$ Polybond 3200 maleic anhydride-grafted polypropylene (MAPP) by PP weight was added to the composites to improve the adhesion between glass fibres and PP matrix. The processing barrel zone temperatures were set to $170{ }^{\circ} \mathrm{C}-220{ }^{\circ} \mathrm{C}$. The extruded material was drawn through a water bath and cut into pellets using a rotary cutter. The pellets were fed into an Arburg 170-90/200' injection moulding machine to produce dog-bone shaped multipurpose test specimens (ISO 3167, Type B). The barrel temperatures were set to $210{ }^{\circ} \mathrm{C}-230{ }^{\circ} \mathrm{C}$ and the mould temperature was set to $35^{\circ} \mathrm{C}$. The fibre weight fraction of the composites was measured by ashing to be $29.3 \pm 0.3 \mathrm{wt} . \%$. The void content of the composites was determined to $1.2 \pm 0.2 \%$ via density measurements according to ASTM 2734 . 
The tensile tests of the injection moulded composites were guided by the standard ISO 527. An Instron 5996 testing machine was used to perform the tensile tests. Sample strain was recorded with a video extensometer. A constant head displacement rate of 1 $\mathrm{mm} / \mathrm{min}$ was used to test the composites. The PP reference sample was tested with a head displacement rate of $1 \mathrm{~mm} / \mathrm{min}$ up to $3 \%$ strain. Then the head displacement rate was increased to $5 \mathrm{~mm} / \mathrm{min}$. Unnotched Charpy impact test specimens according to ISO 179-1 were cut from injection moulded tensile bars. A Tinius Olsen Impact 503 impact tester with a $25 \mathrm{~J}$ hammer was used to perform the impact tests. Ten individual samples of each system were measured for both tensile and impact testing.

\section{Results and discussion}

\subsection{Thermal Degradation Study}

\subsubsection{TGA of Polypropylene Compatible Glass Fibre Sizings}

Figure 1 presents typical TGA results for weight loss (TGA) and differential weight loss (DTG) of the B1 fibres heated either under an air or nitrogen atmosphere. It is clear that there are major differences in the TGA results depending on the atmosphere used. Given that E-glass is thermally stable in this temperature region it is reasonable to assume that the weight changes observed in Figure 1 are caused primarily by degradation of the organic materials in the fibre sizing. This is further supported by the fact that the average weight loss for B1 fibres at the end of the TGA experiment was $0.50 \pm 0.02 \%$ which is in good agreement with the manufacturer data sheet value for the product loss on ignition value of $0.5 \%$. The results in Figure 1 clearly indicate that the majority of the sizing on these fibres is thermally degraded when heated in an air 
atmosphere in the range $200-250{ }^{\circ} \mathrm{C}$. The maximum rate of weight change is indicated by the peak in the differential mass change data at $242{ }^{\circ} \mathrm{C}$, and the initial temperature for the degradation event is at only $204{ }^{\circ} \mathrm{C}$. The sizing on fibre B1 appears much more thermally stable when heated under a nitrogen atmosphere, indicating that the major degradation event under air is of a thermo-oxidative nature. Under nitrogen fibre B1 does show some weight loss in the $200-300{ }^{\circ} \mathrm{C}$ temperature range but major degradation of the sizing does not occur until the temperature exceeds $350{ }^{\circ} \mathrm{C}$.

To check whether the TGA results observed for fibre B1 were unique we investigated the thermal stability of the sizings on a number of other PP compatible glass fibres available in our laboratory. The results for the TGA weight loss in air for five different glass fibre products are compared in Figure 2. It can be seen that all of these products show a major weight loss event in the temperature range $200-300{ }^{\circ} \mathrm{C}$ when heated in air. Similarly when heated under a nitrogen atmosphere the sizings on these fibres all showed little significant weight loss until above $350{ }^{\circ} \mathrm{C}$. Values obtained for the initiation weight loss temperature $\left(T_{\text {init }}\right)$ and the peak rate of change temperature $\left(\mathrm{T}_{\text {peak }}\right)$ are compared in Table 2. Although there are small differences in the values presented in Table 2 it is clear that all five glass fibre products show a very similar pattern of sizing degradation under the two atmospheres. The chemical composition of glass fibre sizing formulations is held confidential by most manufacturers. However, Thomason has recently reviewed the open literature on sizing [1] and the sizing formulations published in the patents of a number of glass fibre manufacturers [2]. It is clear from these two works that modern PP compatible glass fibre sizings consist primarily of MAPP film former and an APS coupling agent. 
Figure 3 shows TGA results of the degradation of a powder obtained by drying a commercial MAPP film former emulsion (Michelman FGLASS X35). Similar to the PP compatible glass fibre sizings in Figures 1 and 2, the MAPP film former started to degrade between $200{ }^{\circ} \mathrm{C}$ and $250{ }^{\circ} \mathrm{C}$. However, the weight loss and degradation of the MAPP film former in Figure 3 appears to be less rapid than the degradation of the glass fibre sizings in Figure 2. This might also be explained by differences in the surface to volume ratio (SVR). A large SVR usually accelerates the degradation of polymeric materials in TGA experiments. The average diameter of the film former powder particles was measured to be $395 \mu \mathrm{m}$. Glass fibres B1 are cylinders with a $13 \mu \mathrm{m}$ diameter and a sizing coating thickness of less than $1 \mu \mathrm{m}$. Thus, the SVR of the glass fibre sizing was approximately twenty times larger than that of the powdered film former particles. Rudzinski et al performed TGA experiments under nitrogen on PU/APS based sizing both as macroscopic cast films and as sizing on E-glass fibres. They reported that the peak maxima of the degradation of the sizing on the fibre surface were shifted to lower temperatures by up to $100{ }^{\circ} \mathrm{C}$ in comparison related to the degradation of the cast films [13]. In a study comparing the TGA weight loss of sizing on E-glass fibre and cast films of sizing extracted from the same fibres Petersen et al found a similar shift to lower temperatures in the degradation of the sizing on the fibres [19]. The TGA curves in Figure 3 show that the degradation of the film former was less rapid in a nitrogen atmosphere than in air. The main peak in the DTG curve is shifted to higher temperatures at approximately $460{ }^{\circ} \mathrm{C}$. A comparison between Figure 3 and Figures 1 and 2 reveals that the curves are similar. Thus, the glass fibre sizings and the MAPP film former degraded in a similar manner in a nitrogen rich atmosphere. This agrees with the hypothesis that the glass fibre thermoplastic compatible sizings degrade 
more rapidly in air than the MAPP film former because of the larger surface area that was in contact with oxygen.

Figure 4 shows the results of a TGA study of thermal degradation APS film under air and nitrogen atmospheres. The film was prepared by drying a $1 \%$ solution of APS for 24 hours at $105{ }^{\circ} \mathrm{C}$. In both cases the APS film exhibited weight loss in the $50-200{ }^{\circ} \mathrm{C}$ range. Jenkins et al have shown that weight loss from APS in this region is due to water elimination from further hydroxyl group condensation and from desorption of carbon dioxide from carbamate formed by interaction with the silane amine group [20]. Above $200{ }^{\circ} \mathrm{C}$ there is a significant difference in the degradation of APS dependent on the atmosphere. In air there is a weight loss event at approximately $245^{\circ} \mathrm{C}$ and then a more significant weight loss starting above $300{ }^{\circ} \mathrm{C}$ and peaking at about $390{ }^{\circ} \mathrm{C}$. Under nitrogen it appears than the APS is relatively stable until the temperature exceeds 400 ${ }^{\circ} \mathrm{C}$ with peak degradation around $460{ }^{\circ} \mathrm{C}$. Tiefenthaler and Urban [21] also studied the thermal stability of APS coated ceramic fibres exposed heated for one hour at different temperatures in air. Their photoacoustic-FTIR study measured relative changes in intensity of the C-H stretching band as a method of analysing sizing loss. They showed by this method that, following a $200{ }^{\circ} \mathrm{C}$ treatment, almost $50 \%$ of the APS coupling agent was gone and by $300{ }^{\circ} \mathrm{C}$ none at all was detected. Hence it seems quite possible that the two main components of PP compatible sizings in the thin sizing layer on glass fibres are prone to thermo-oxidative degradation in the $200-300{ }^{\circ} \mathrm{C}$ temperature range.

\subsubsection{TGA of Epoxy Compatible Glass Fibre Sizings}

Despite the fact that glass fibre thermosetting composites are typically processed at temperatures well below those necessary for thermoplastic composites there are high 
temperature curing thermosetting systems and also local exotherm during curing can result in local temperature spikes. It was therefore deemed interesting to extend the study of sizing thermal degradation to thermoset compatible glass fibres. Figure 5 show the weight loss curves and DTG of glass fibres O1. The experiments were performed in air and in a nitrogen rich atmosphere. Both epoxy compatible glass fibre samples (O1 and P4) exhibited a similar mass loss which can be explained with a similar glass fibre sizing formulation $[1,2]$ and datasheet LOI values. Figure 5 reveals that the total weight loss due to the degradation of the glass fibre sizing was higher when the TGA was performed in air. This phenomenon has been observed by others [8] and can be explained with the formation of char on the fibre surface when the TGA is performed in a nitrogen rich atmosphere. Values obtained for the initiation weight loss temperature ( $\left.\mathrm{T}_{\text {init }}\right)$ and the peak temperature(s) $\left(\mathrm{T}_{\text {peak }}\right)$ in the DTG curves are compared in Table 3. The onset of degradation was at around $250{ }^{\circ} \mathrm{C}$ in air and slightly higher, around 280 ${ }^{\circ} \mathrm{C}$, under a nitrogen atmosphere. The peaks in the DTG curves in Figure 5 show that the main degradation peak temperature under nitrogen is shifted approximately $60{ }^{\circ} \mathrm{C}$ higher than that obtained in air. Similar observations were reported by Feih et al [8] in their study of the thermal degradation of glass fibres with an epoxy compatible sizing.

It is well known the epoxy compatible sizings also usual contain a large fraction of epoxy resin, often a version of a diglycydylether of bisphenol-A (DGEBA) [1,2,19,22]. Figure 6 shows the TGA weight loss curve of a sample of DGEBA (DER332) obtained under air. It can clearly be seen that the thermal degradation of DGEBA is primarily a single-step process when performed in air. The overlaid TGA curve from fibre $\mathrm{O} 1$ (normalised to weight of sizing on the fibres) indicates that the first degradation event in the sizing occurs at the same temperature as that of pure epoxy resin. This first event 
also accounts for $60-70 \%$ of the sizing weight loss. Analysis of glass fibre sizing formulations indicates that epoxy compatible sizings typically contain $60-70 \%$ of epoxy resin [2]. Other primary components for epoxy compatible sizings tend to be epoxysilane, ethoxylated surfactants, and polyethyleneglycol type lubricants $[2,19,22]$. Of these three possibilities it seems likely that the epoxysilane is the component responsible for the further weight loss from fibres $\mathrm{O} 1$ and $\mathrm{P} 4$ in the $350-500{ }^{\circ} \mathrm{C}$ temperature range.

The DTG curves of the two epoxy sizings studied exhibited a second minor peak at around $430{ }^{\circ} \mathrm{C}$ when the TGA was performed in air (see Figure 5 and Table 3). This is the same temperature range in Figure 4 where the silane film exhibits a degradation event and so the second peak in the degradation of both epoxy sizings in air might have been caused by the degradation of the silane. Petersen et al also analysed the sizing on Jushi 320, a thermoset multicompatible E-glass fibre product, using various methods including TGA (in air) of sizing extract and the sizing on the glass [19]. They concluded from their TGA that the sizing consisted mainly of two components with different decomposition temperatures. They further concluded from infrared analysis techniques that the sizing contained $67 \%$ film former and $19 \%$ silane. Their TGA weight loss curve for the sizing degradation on the fibres showed two major degradation events at $320{ }^{\circ} \mathrm{C}$ and $420-460{ }^{\circ} \mathrm{C}$ which appeared to be very similar to our results in Figure 5. Nevertheless, as previously stated the processing temperatures for glass fibre epoxy composites are often much lower than those for thermoplastic composites and certainly below the $\mathrm{T}_{\text {init }}$ values shown in Table 3. Consequently, in terms of composite performance, it could be assumed that degradation of epoxy compatible sizings may not be such a significant issue as that observed above for PP compatible sizing. 


\subsection{Microbond Testing of IFSS}

Given the fact that fibre sizing plays a most significant role in determining the level of apparent adhesion in composites, microbond tests were performed to provide a direct measure of the interfacial shear strength (IFSS) between thermally conditioned B1 chopped glass fibres and PP and thermally condition continuous glass fibres $\mathrm{O} 1$ and two epoxy resin systems. The results for IFSS as a function of fibre pretreatment temperature for fibre $\mathrm{O} 1$ in two epoxy resin systems are shown in Figure 7. At least thirty samples were tested for each pretreatment temperature. The success rate at each condition was generally $80-90 \%$. Both systems are stoichiometric mixtures of TETA with either Araldite 506 (a DGEBA epoxy containing an epoxidised reactive diluent) or DER332 (a low viscosity DGEBA epoxy). As has been previously observed [16-18] there was some small meniscus left on most of the fibres after droplet debonding. However, there was little evidence of significant differences in the size of the remaining meniscus depending on the fibre heat treatment temperature. It can be seen that in both resin systems the IFSS is approximately constant up to a pretreatment temperature of $300{ }^{\circ} \mathrm{C}$. Above this temperature the apparent fibre-matrix adhesion decreases significantly and then levels out above $400{ }^{\circ} \mathrm{C}$. Fibre OW had approximately the same IFSS of 38.5 MPa in both epoxy systems. It is notable that sized fibre O1 pretreated at $400{ }^{\circ} \mathrm{C}$ and higher has a lower IFSS than the IFSS for unsized glass fibre OW (with no heat treatment) in the same resin systems. This may be due to the fact that that some of the higher IFSS values are missing from the overall average value due to premature tensile failure of the weakened fibres after the $400-500^{\circ} \mathrm{C}$ heat treatment $[10,11]$. Another possible explanation is that there may well be residual carbonized sizing 
material on the fibre surfaces. It might be suggested (as in the case on carbon fibres which have not be surface activated) that such a surface provides a poorer interaction with the epoxy resin matrix than the hydroxyl rich surface of the water sized fibres OW.

Figure 7 also contains an overlay of the TGA weight loss results for fibre O1. It is clear that the steep loss in IFSS for fibre pretreated above $300{ }^{\circ} \mathrm{C}$ correlates well with weight loss of the sizing on these fibres at similar temperatures. Consequently we conclude that the loss in IFSS is associated with a loss of adhesion enhancing capability of the sizing on these epoxy compatible fibres. If the adhesion enhancing capabilities of such sizings is associated primarily with chemical bonding at the interface then it is not immediately obvious why degradation of the film former components would reduce the chemical bonding potential of the sizing. It is more likely that degradation of the silane coupling agent could be the issue. On the other hand it has recently been shown that silane coupling agents alone do not contribute much to the IFSS of glass fibres in these two resin systems $[23,24]$.

The microbond testing results for the investigation of the apparent IFSS of thermally pretreated glass fibre B1 in PP are presented in Figure 8. The data shows a similar trend to the results for the epoxy compatible samples in Figure 7. For fibres pre-treated in an air atmosphere the apparent IFSS was relatively stable up to $200{ }^{\circ} \mathrm{C}$ and then dropped sharply in the range between $200{ }^{\circ} \mathrm{C}$ and $250{ }^{\circ} \mathrm{C}$ fibre preconditioning temperature. Higher preconditioning temperatures did not cause a further significant drop when the 95\% confidence limit error bars are considered. However, the thermal preconditioning of the glass fibres up to $300{ }^{\circ} \mathrm{C}$ in nitrogen rich atmosphere did not cause a reduction of the IFSS. The IFSS then decreased steeply between $300{ }^{\circ} \mathrm{C}$ and $400{ }^{\circ} \mathrm{C}$ fibre preconditioning temperature and decreased further at $500{ }^{\circ} \mathrm{C}$. At $500{ }^{\circ} \mathrm{C}$ fibre 
preconditioning temperature the IFSS was independent from the atmosphere and was approximately the same as the IFSS of $8 \mathrm{MPa}$ for bare fibre OW [17]. With the PP droplets there was negligible meniscus left on the fibres after debonding with any of the samples. This is probably due to the relatively low levels of adhesion exhibited by the PP droplets, especially to the fibres heat treated above $200{ }^{\circ} \mathrm{C}$. The data in Figure 8 would appear to support the conclusion that commercial glass fibre sizings lose their adhesion enhancing capabilities when they are exposed to high temperatures $\left(500{ }^{\circ} \mathrm{C}\right.$ and above) independent of the atmosphere. However, it also appears that these fibres lose their ability to deliver high levels of interfacial strength when exposed to normal PP composite processing temperatures $\left(200^{\circ} \mathrm{C}-300^{\circ} \mathrm{C}\right)$ in an air atmosphere.

It is interesting to note that the trends for IFSS observed in Figure 8 are very similar to the overlaid trends for the TGA sizing weight loss data from Figure 1. The upward shift in the position of the main mass loss in comparison to the loss in IFSS may well be due to the dynamic heating of the TGA experiment in comparison to the isothermal heat treatment of the fibres used for IFSS. It was also discussed above that degradation of the MAPP used in the fibre sizing might be a possible cause of this issue. The matrix used in the microbond samples in Figure 8 did not contain additional MAPP and hence degradation of the MAPP in the sizing would remove any MAPP functionality from the system, which could explain the loss of adhesion. Microbond results for the IFSS of fibre B1 in a PP with 1\% MAPP matrix are presented in Figure 9. The initial values of the IFSS are higher than in Figure 8 because of the added MAPP. However, here again the IFSS dropped sharply between $200{ }^{\circ} \mathrm{C}$ and $250{ }^{\circ} \mathrm{C}$ preconditioning temperature. So we observe the same sharp drop in the IFSS performance of fibre B1 pretreated above $200{ }^{\circ} \mathrm{C}$ whether or not there is MAPP added to the PP matrix. This would seem to 
indicate that the loss in IFSS performance may not be primarily caused by a loss in MAPP functionality in the sizing.

It is also interesting to note that fibre P2 from a different manufacturer with their proprietary sizing also shows a sharp drop in IFSS when thermally preconditioned above $200{ }^{\circ} \mathrm{C}$. This would seem to support the implication of the TGA results, that the different glass fibre producers used very similar constituents in their sizings. Figure 9 also shows the IFSS between PP with $1 \%$ MAPP and unsized boron free E-glass fibres (OW). The value of the IFSS between unsized fibres and PP with $1 \%$ added MAPP is similar to the value for fibres that were thermally preconditioned at $500{ }^{\circ} \mathrm{C}$. Thus, the sizing was probably completely degraded when the fibres were exposed to $500{ }^{\circ} \mathrm{C}$ in air and even the fibres preconditioned at $250{ }^{\circ} \mathrm{C}$ apparently provided little better IFSS performance than unsized fibres. This would seem to imply that the drop in performance of the fibre preconditioned at $250{ }^{\circ} \mathrm{C}$ may not be primarily due to the degradation of the MAPP component of the film former. Consequently it was deemed worthwhile to further investigate the effect of thermal preconditioning on fibres OA which were sized only with APS coupling agent.

The amount of organic material on fibres sized with a $1 \%$ silane solution is extremely small and TGA experiments showed little significant weight change. However, significant changes in adhesion performance were observed. The results of microbond testing of thermally preconditioned APS coated fibres in PP containing 1\% MAPP are shown in Figure 10. Within the 95\% confidence limits the IFSS for the APS fibre is constant up to $200{ }^{\circ} \mathrm{C}$. The IFSS then takes a step down between $200{ }^{\circ} \mathrm{C}$ and 250 ${ }^{\circ} \mathrm{C}$, is constant between $250{ }^{\circ} \mathrm{C}$ and $300{ }^{\circ} \mathrm{C}$ and then reduces linearly with increasing temperature up to $500{ }^{\circ} \mathrm{C}$. Hence the APS coated fibres do appear to show some initial 
loss of adhesion functionality when conditioned at $250^{\circ} \mathrm{C}$, but the relative reduction in IFSS does not seem to be as severe as observed in Figures 8 and 9 with the fully sized commercial fibres. Further investigation of sizing stability using controlled formulations with known ingredients would appear to be the way forward to clarify these findings.

\subsection{Composite Performance}

The tensile strength of the injection moulded composites is plotted in Figure 11 as a function of the fibre preconditioning temperature in air. The composite tensile strength dropped sharply between $200{ }^{\circ} \mathrm{C}$ and $250{ }^{\circ} \mathrm{C}$ fibre preconditioning temperature. Higher fibre preconditioning temperatures caused a further reduction of the composite strength. After fibre preconditioning at $500{ }^{\circ} \mathrm{C}$ the composite strength dropped to $37.7 \pm 0.5 \mathrm{MPa}$ which is barely higher than the tensile strength of the unreinforced PP $(35.8 \pm 0.2 \mathrm{MPa})$. The unnotched Charpy impact strength of the composites in Figure 11 followed a very similar trend as the composite strength. A sharp drop was observed between $200{ }^{\circ} \mathrm{C}$ and $250{ }^{\circ} \mathrm{C}$ fibre preconditioning temperature. Figure 12 shows SEM micrographs taken of the fracture surfaces of the unnotched Charpy impact samples. Although there is still some discussion about the validity use of such micrographs to characterize the state of the fibre-matrix adhesion [25] many authors form opinions on the level of adhesion depending on the amount of residual polymer attached to the fibres in such micrographs. The images for the composite produced using as received fibres and fibres which had been heat treated at $200{ }^{\circ} \mathrm{C}$ show fibres pulled out of the fracture surface still well coated in organic material. This is often taken as evidence of a good level of fibrematrix adhesion in the composite. In contrast the composites produced with fibres heat treated at $250{ }^{\circ} \mathrm{C}$ and higher the fibres pulled out of the fracture surface appeared to be very clean and devoid of any organic material adhering to the fibres. This highly visible 
change in the appearance of the fibres of the composite fracture surfaces which appears when the fibre heat treatment temperature is raised from $200{ }^{\circ} \mathrm{C}$ to $250{ }^{\circ} \mathrm{C}$ correlates closely with the large decrease in the IFSS results obtained using the microbond test shown in Figure 9.

Thermal pretreatment of glass fibres above $350-400{ }^{\circ} \mathrm{C}$ has been shown to cause a significant drop in the fibre strength $[8,10,11]$ however the sharp drop in composite performance shown in Figure 11 occurs at much lower temperature. Furthermore this severe drop in composite performance occurs in what can be considered the normal processing temperature range for PP based composites and appears to correlate well with the drop in adhesion performance discussed in Figures 8 and 9. In fact, with appropriate adjustment of the scales, it is possible to overlay the IFSS results and the composite tensile strength and impact data with the TGA mass loss data for the sizing on fibre B1. This is shown in Figure 13 where the close correlation in all four data sets can be observed. Furthermore it should be noted when comparing the results from the isothermal heat treatment of the fibre on IFSS and composite properties with the TGA data that the TGA is a dynamic heating experiment and so the apparent temperature position of events is usually shifted to higher temperatures in comparison with isothermal experiments. It is likely that this explains the slight upward shift in temperature of the step down observed in the TGA mass loss data in Figure 13 and in fact there is actually excellent correlation between the results from all four types of measurement.

\section{Conclusions}


Thermal analysis results revealed that the sizings on epoxy compatible glass fibre are relatively stable up to $250{ }^{\circ} \mathrm{C}$ in both nitrogen and air atmospheres. At higher temperatures the epoxy resin component of the sizing degrades relatively rapidly. Fibres thermally conditioned above this temperature exhibited a significant loss in interfacial adhesion with amine cured epoxy systems. Of potentially greater concern were thermal analysis results which showed that the sizings on a range of commercially produced PP compatible glass fibre degrade in air at temperatures that are used in PP composite processing. The PP sizing degradation occurred in air above $200{ }^{\circ} \mathrm{C}$ and under inert atmosphere above $300{ }^{\circ} \mathrm{C}$. Microbond tests showed that the sizing degradation resulted in a sharp reduction of the interfacial strength between fibres and PP. The tensile strength and unnotched Charpy impact strength of injection moulded GF-PP composites also dropped sharply when the fibres were thermally preconditioned above $200{ }^{\circ} \mathrm{C}$ in air before composite processing. Although the thermal preconditioning used here is not necessarily similar to commercial composite processing conditions, the results do show that PP compatible sizings are highly susceptible to thermal degradation in air. Further research is required to assess if PP compatible sizings are also thermally degraded during hot melt processing.

\section{Acknowledgements}

The authors would also like to acknowledge the financial support from Engineering and Physical Sciences Research Council and the assistance of the Advanced Materials Research Laboratory of the University of Strathclyde with the testing. The authors also 
would like to thank 3B Fibreglass, PPG Fibre Glass, Owens Corning, and SABICEurope for providing materials used in this study. 


\section{References}

1. Thomason JL. Glass fibre sizing: A review of the scientific literature. Blurb Inc., 2012, ISBN 9780957381414.

2. Thomason JL., Glass fibre sizing: A review of size formulation patents. Blurb Inc. 2015, ISBN 9780957381438.

3. Loewenstein KL, Glass science and technology 6, The manufacturing technology of continuous glass fibres. Amsterdam: Elsevier, 1993.

4. Berg J, Jones FR. The role of sizing resins, coupling agents and their blends on the formation of the interphase in glass fibre composites. Compos Part A Appl Sci Manuf 1998;29:1261-1272.

5. Larson BK, Drzal LT. Glass fibre sizing/matrix interphase formation in liquid composite moulding: effects on fibre/matrix adhesion and mechanical properties. Composites 1994;25:711-721.

6. Mäder E, Study of fibre surface treatments for control of interphase properties in composites, Compos Sci Tech 1997;57:1077-1088.

7. Thomason JL. The interface region in glass fibre-reinforced epoxy resin composites : 1.Sample preparation, void content and interfacial strength. Composites $1995 ; 26: 467-75$.

8. Feih S, Boiocchi E, Mathys G, Mathys Z, Gibson AG, Mouritz AP. Mechanical properties of thermally-treated and recycled glass fibres. Compos Part B Eng 2011;42:350-358.

9. Yang L, Thomason JL. Effect of silane coupling agent on mechanical performance of glass fibre. J Mater Sci 2012;48:1947-54.

10. Thomason JL, Yang L, Meier R. The properties of glass fibres after conditioning at composite recycling temperatures. Compos Part A Appl Sci Manuf 2014;61:201-8.

11. Thomason JL, Jenkins P, Yang L. Glass fibre strength - a review with relation to composite recycling. Fibers 2016;4(2):18.

12. Nagel U, Yang L, Kao CC, Thomason JL. Effects of thermal recycling temperatures on the reinforcement potential of glass fibers Polym Compos 2018:39:1032-1040. 
13. Rudzinski S, Häussler L, Harnisch C, Mäder E, Heinrich G. Glass fibre reinforced polyamide composites: Thermal behaviour of sizings. Compos Pt A Appl Sci Manuf 2011;42:157-164.

14. Moosburger-Will J, Bauer M, Laukmanis E, Horny R, Wetjen D, Manske T, Schmidt-Stein F, Töpker J, Horn S. Interaction between carbon fibers and polymer sizing: Influence of fiber surface chemistry and sizing reactivity, Appl Surf Sci 2018;439:305-312.

15. Duchoslav J, Unterweger C, Steinberger R, Fürst C, Stifter D. Investigation on the thermo-oxidative stability of carbon fiber sizings for application in thermoplastic composites. Polym Degrad and Stab 2016;125:33-42.

16. Yang L, Thomason JL. Development and application of micromechanical techniques for characterising interfacial shear strength in fibre-thermoplastic composites. Polym Test 2012;31:895-903.

17. Thomason JL, Yang L. Temperature dependence of the interfacial shear strength in glass-fibre polypropylene composites. Compos Sci Technol 2011;71:1600-1605.

18. Thomason JL, Yang L. Temperature dependence of the interfacial shear strength in glass-fibre epoxy composites. Compos Sci Technol 2014;96:7-12.

19. Petersen, HN, Kusano, Y, Brøndsted, P \& Almdal, K 2014, Analysis of glass fibre sizing. in Proceedings of the 28th International Conference on Surface Modification Technologies. 28th International Conference on Surface Modification Technologies, Tampere, Finland, June, 2014.

20. Jenkins PG, Understanding physical changes and strength loss of E-glass fibres following exposure to elevated temperatures. Mater Sci Technol, 2017;33:255-264.

21. Tiefentahaler AM, Urban MW. Thermal stability of silane coupling agents on Nextel fibres. Composites, 1999;20:145-150.

22. Thomason JL. The interface region in glass fibre-reinforced epoxy resin composites: Part 3 Characterisation of fibre surface coatings and the interphase. Composites 1995;26:487-498.

23. Thomason JL, Yang L, Minty R. Are silanes the primary driver of interface strength in glass fibre composites?: exploring the relationship of the chemical and physical parameters which control composite interfacial strength. Proceedings of ECCM18. Athens, June, 2018. 
24. Bryce D, Yang L, Thomason JL. An investigation of fibre sizing on the interfacial strength of glass-fibre epoxy composites, Proceedings of ECCM18. Athens, June, 2018.

25. Fu SY, Lauke B, Zhang YH, Mai Y-W. On the post-mortem fracture surface morphology of short fiber reinforced thermoplastics. Compos Part A Appl Sci Manuf 2005;36:987-994. 


\section{Tables}

Table 1. Glass fiber products used in this study.

\begin{tabular}{cllccc}
\hline Fibre & Product Code & Source & Diameter & Tex & LOI (\%) \\
\hline B1 & DS 2200-13P & 3B Fibreglass & 13 & chopped & 0.6 \\
B2 & SE 4220 & 3B Fibreglass & 17 & 2400 & 0.3 \\
P1 & LFT4000 & PPG Fiber Glass & 24 & 4400 & 0.45 \\
P2 & TUFRov4575 & PPG Fiber Glass & 17 & 2400 & 0.6 \\
P3 & TUFRov4599 & PPG Fiber Glass & 17 & 2400 & 0.4 \\
P4 & Hybon 2002 & PPG Fiber Glass & 17 & 2400 & 0.55 \\
O1 & SE1500 & Owens Corning & 17 & 2400 & 0.65 \\
OA & APS sized & Owens Corning & 17 & 1200 & $<0.1$ \\
OW & Water sized & Owens Corning & 17 & 1200 & 0 \\
\hline
\end{tabular}

Table 2. Characteristic temperatures from TGA scans of PP compatible fibres.

\begin{tabular}{c|cc|cc}
\hline & \multicolumn{2}{|c|}{ Air } & \multicolumn{2}{c}{ Nitrogen } \\
Fiber & $\mathrm{T}_{\text {init }}\left({ }^{\circ} \mathrm{C}\right)$ & $\mathrm{T}_{\text {peak }}\left({ }^{\circ} \mathrm{C}\right)$ & $\mathrm{T}_{\text {init }}\left({ }^{\circ} \mathrm{C}\right)$ & $\mathrm{T}_{\text {peak }}\left({ }^{\circ} \mathrm{C}\right)$ \\
\hline B1 & 204 & 242 & 312 & 463 \\
B2 & 219 & 238 & 308 & 462 \\
P1 & 225 & 250 & 324 & 460 \\
P2 & 240 & 253 & 320 & 460 \\
P3 & 227 & 249 & 315 & 464 \\
FGLASS X35 & 230 & 345 & 234 & 465 \\
\hline
\end{tabular}

Table 3. Characteristic temperatures from TGA scans of epoxy compatible fibres.

\begin{tabular}{c|ccc|cc}
\hline & \multicolumn{3}{|c|}{ Air } & \multicolumn{2}{c}{ Nitrogen } \\
Fiber & $\mathrm{T}_{\text {init }}\left({ }^{\circ} \mathrm{C}\right)$ & $\mathrm{T}_{\text {peak1 } 1}\left({ }^{\circ} \mathrm{C}\right)$ & $\mathrm{T}_{\text {peak2 }}\left({ }^{\circ} \mathrm{C}\right)$ & $\mathrm{T}_{\text {init }}\left({ }^{\circ} \mathrm{C}\right)$ & $\mathrm{T}_{\text {peak }}\left({ }^{\circ} \mathrm{C}\right)$ \\
\hline O1 & 245 & 302 & 428 & 280 & 365 \\
P4 & 254 & 309 & 433 & 283 & 364 \\
DER332 & 257 & 325 & & 255 & 330 \\
\hline
\end{tabular}




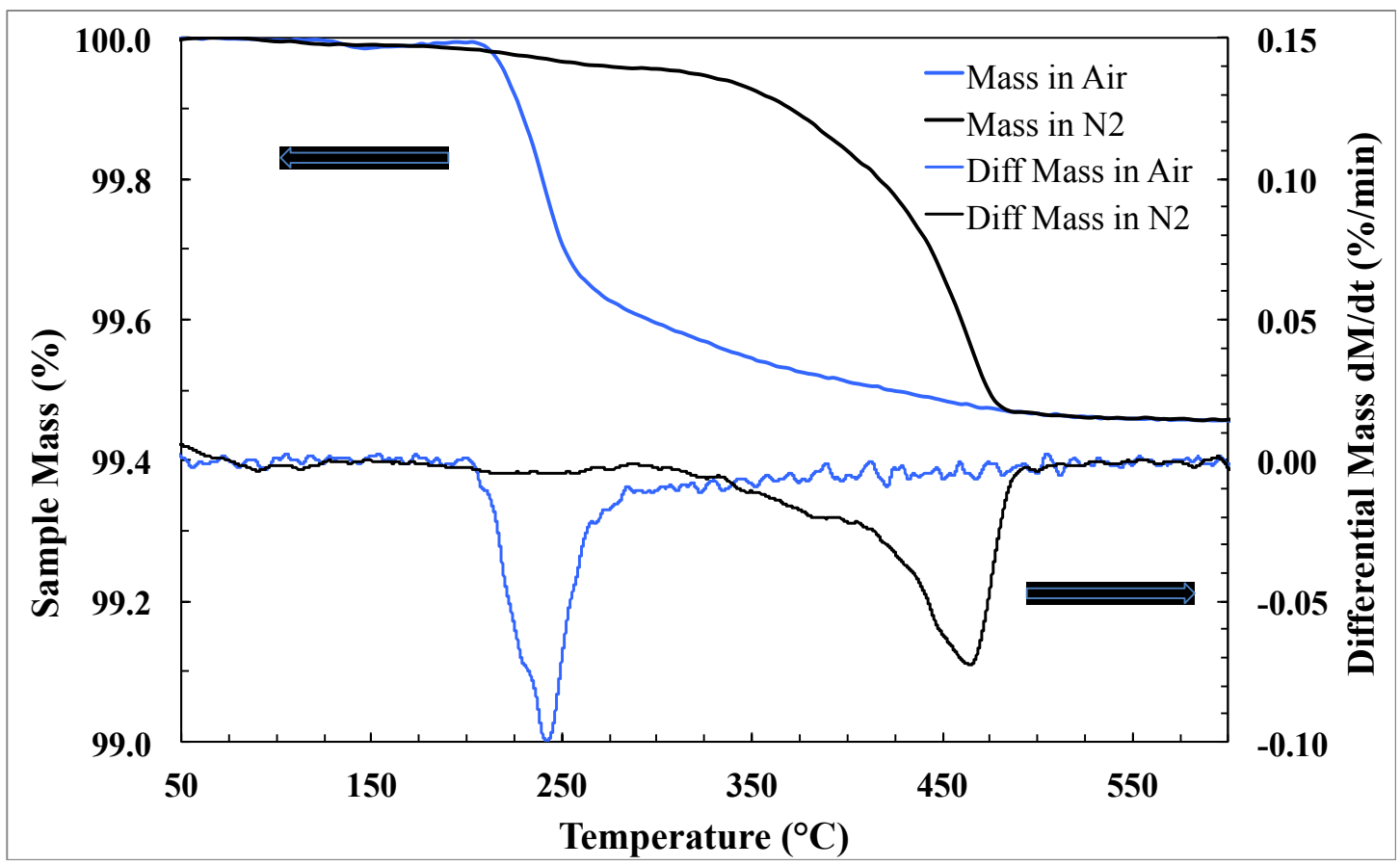

Figure 1 TGA and DTG curves from PP compatible fibre B1 in air or nitrogen atmosphere

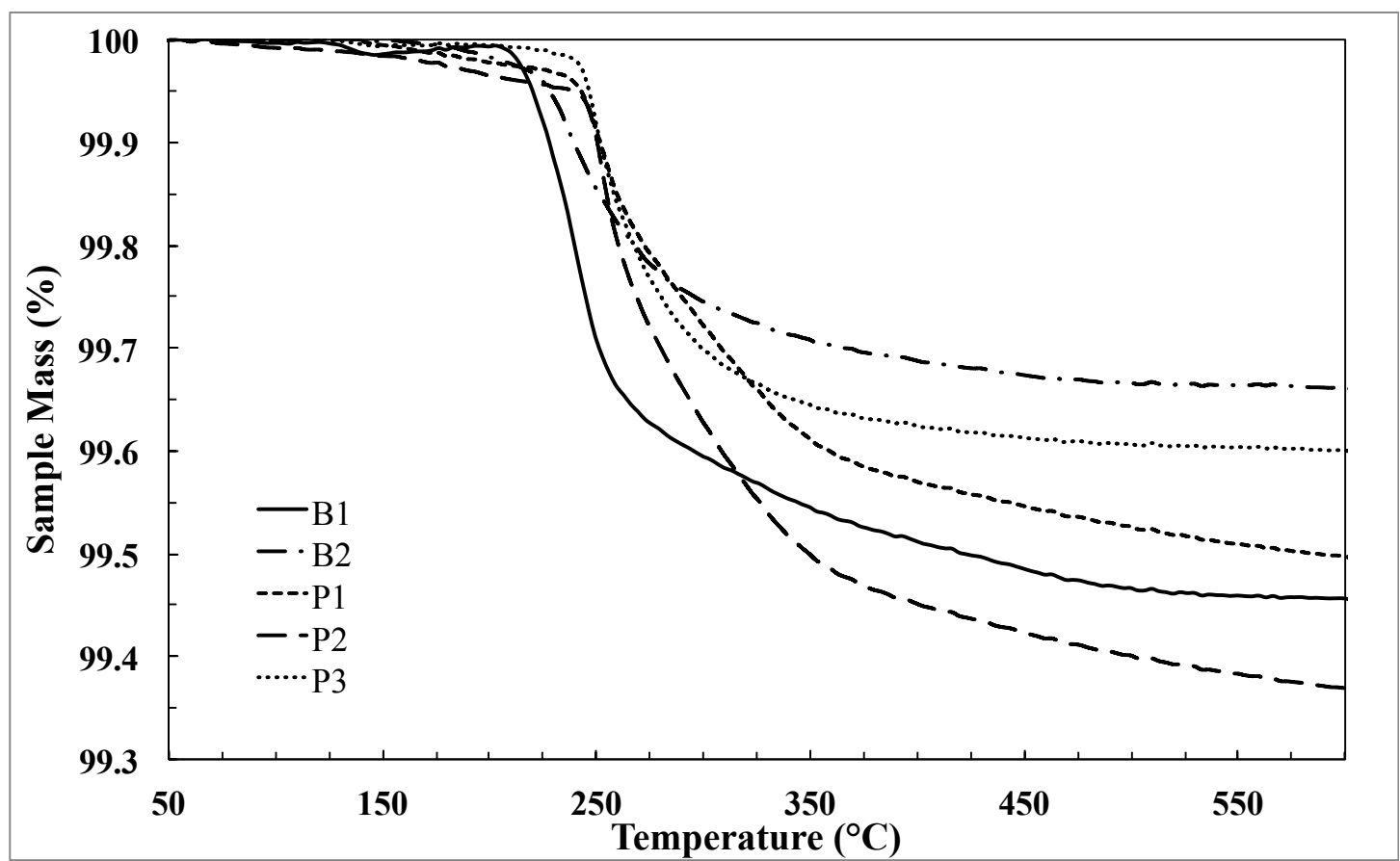

Figure 2 Comparison of TGA curves from five PP compatible glass fibre products heated in air 


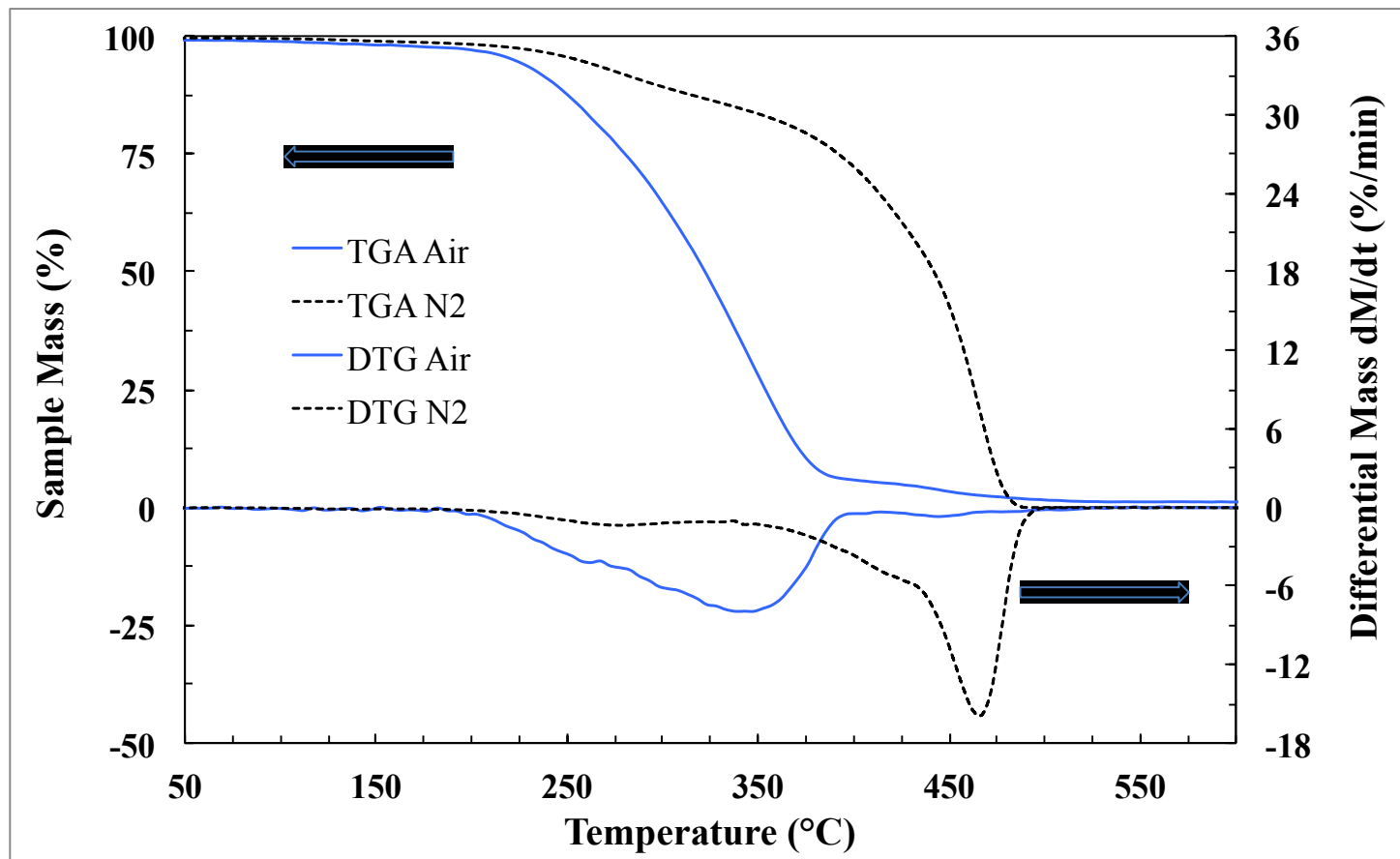

Figure 3 TGA and DTG curves from dried MAPP film former

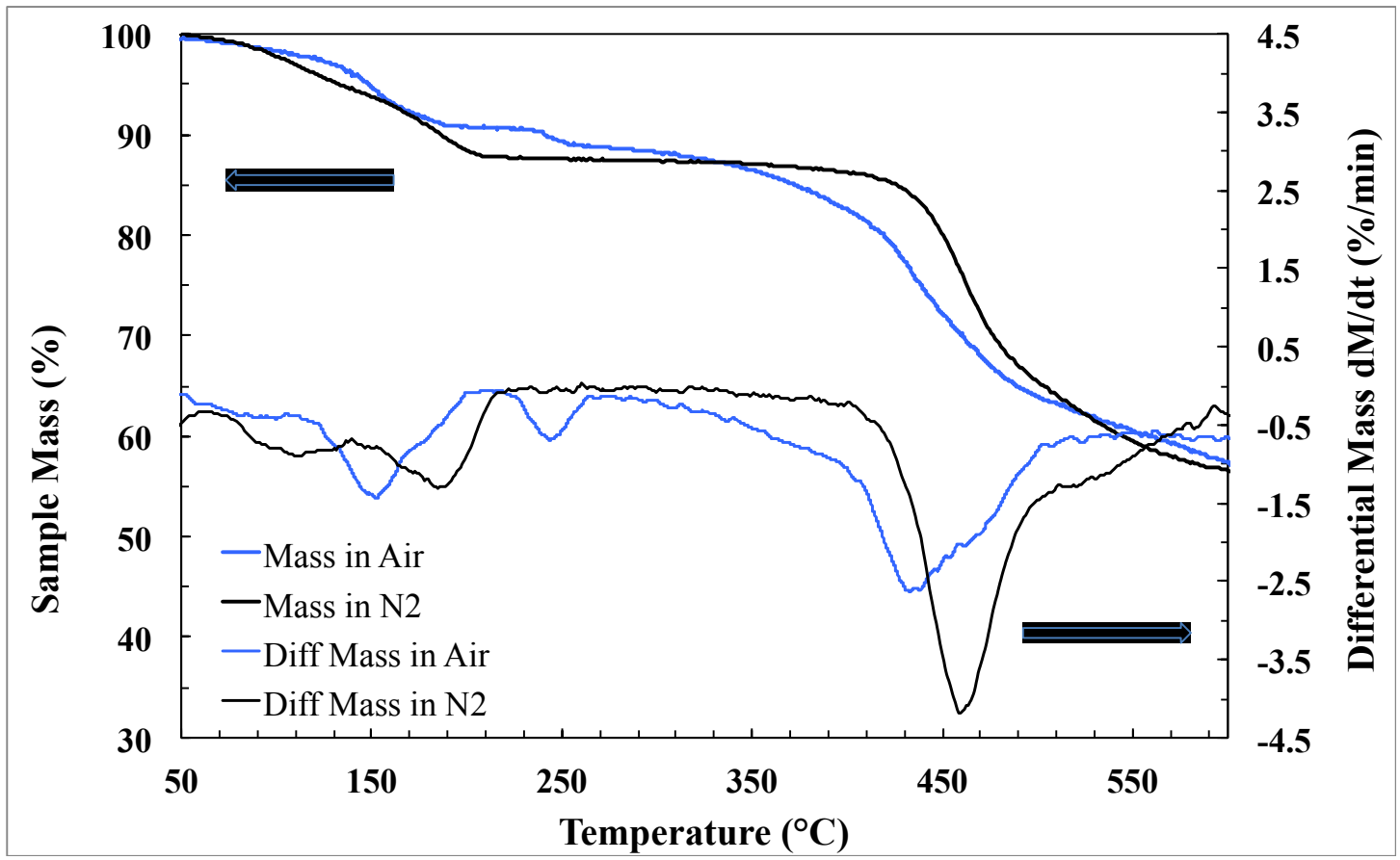

Figure 4 TGA and DTG curves from dried APS film 


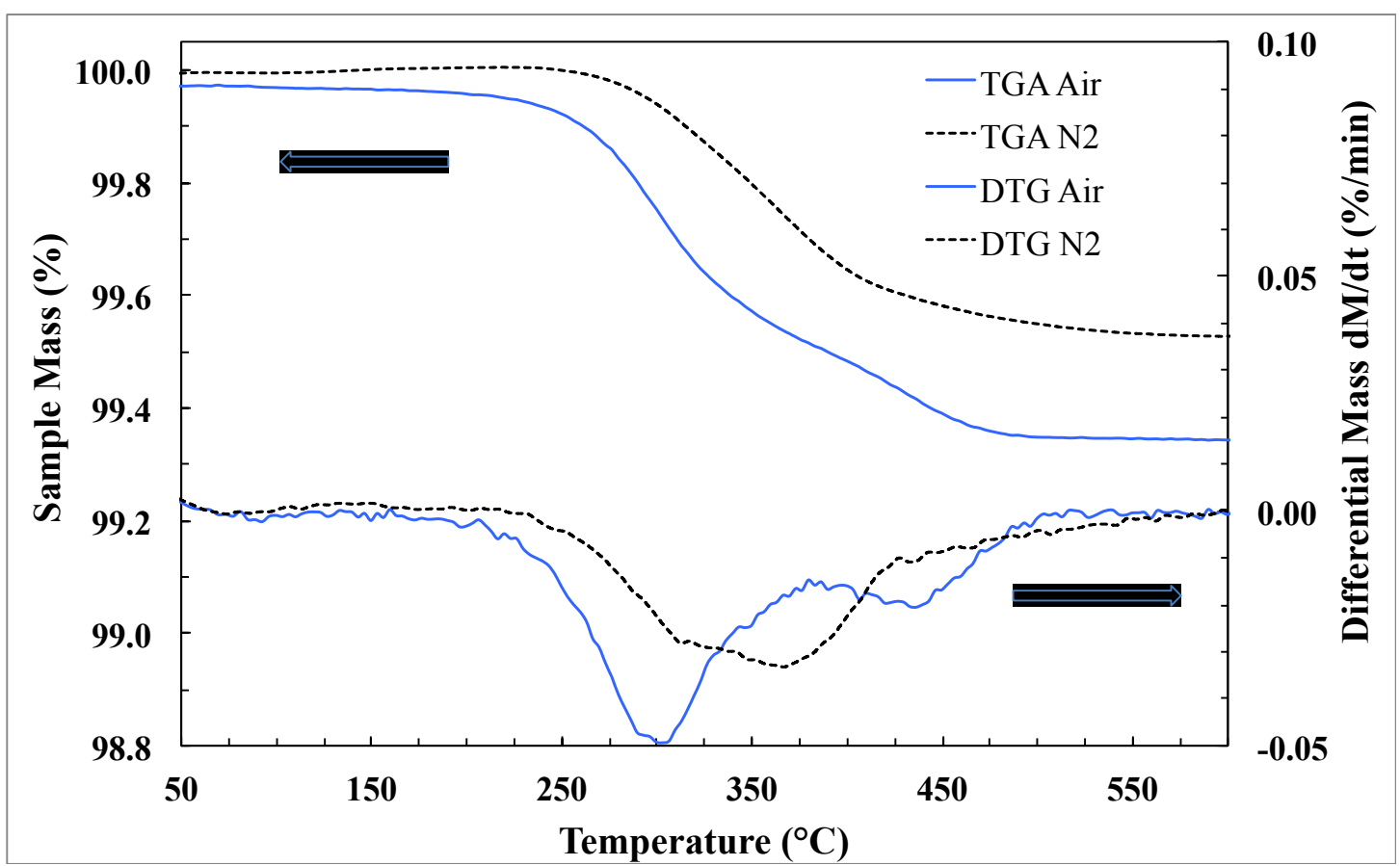

Figure 5 TGA and DTG curves from epoxy compatible fibre O1

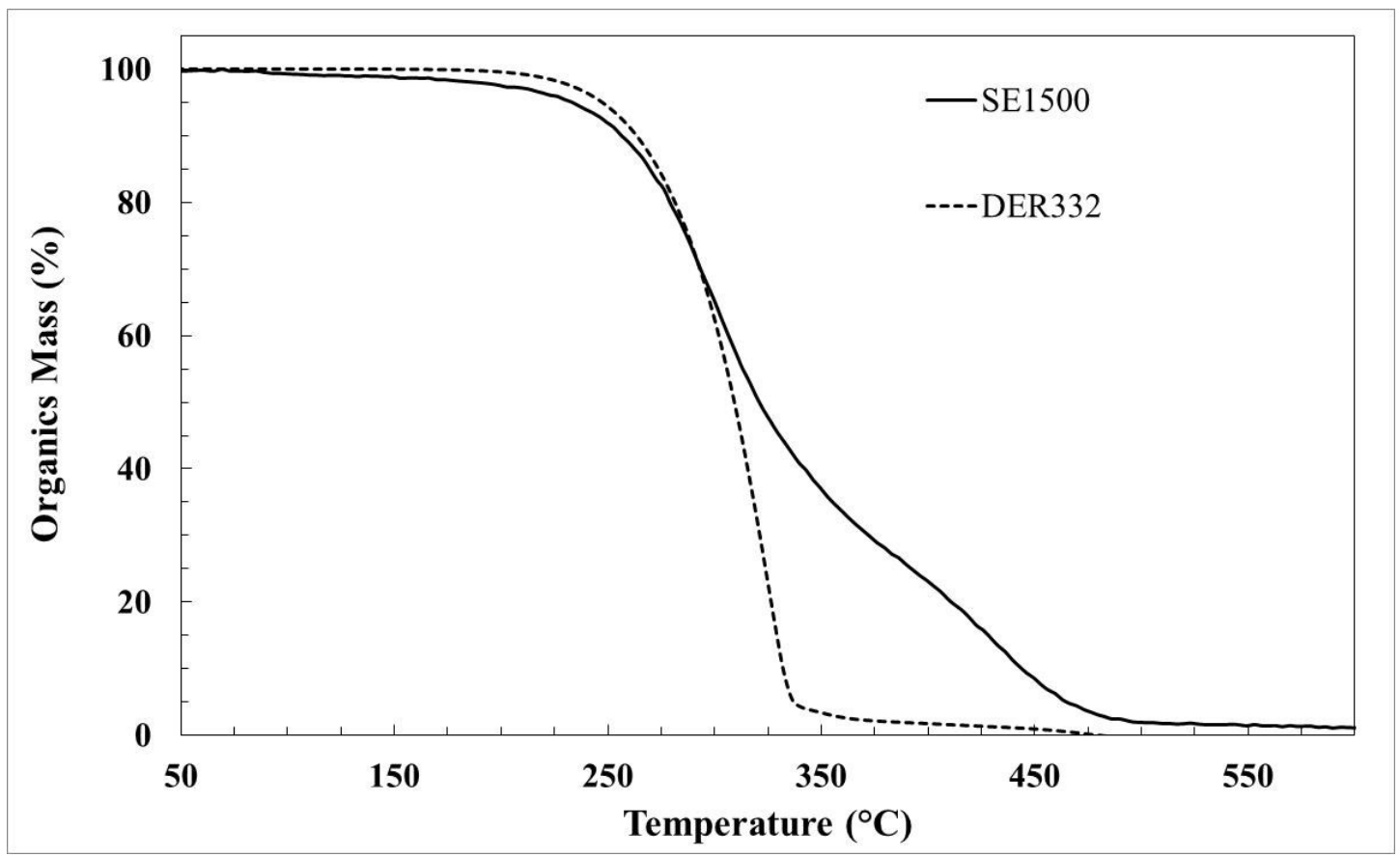

Figure 6 Comparison of TGA in air of Fibre O1 and DER332 DGEBA epoxy resin 


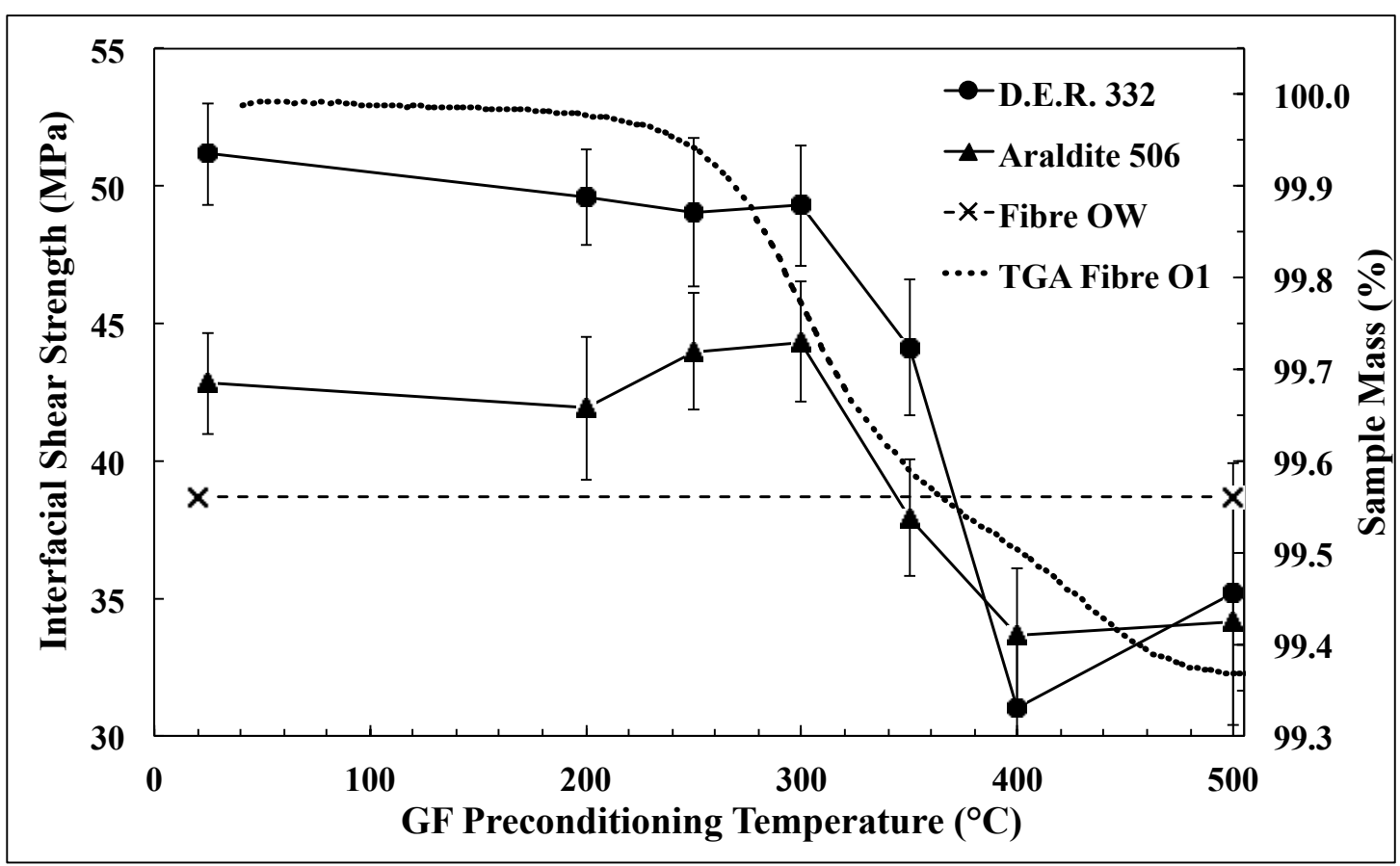

Figure 7 Effect of fibre preconditioning temperature in air on IFSS performance of fibre O1 in two TETA cured DGEBA epoxy resins

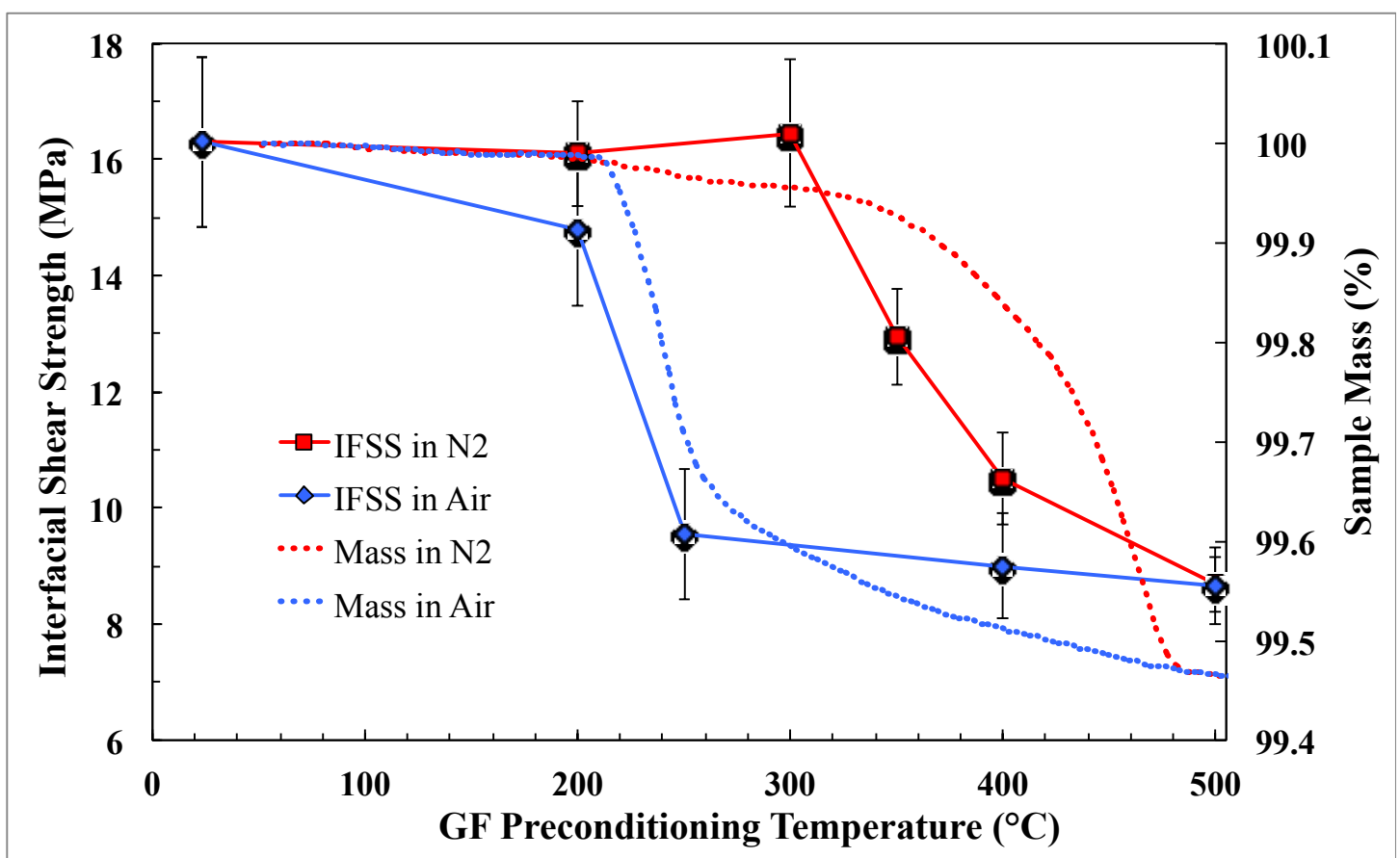

Figure 8 Effect of fibre preconditioning temperature on IFSS performance of fibre B1 in homopolymer PP 


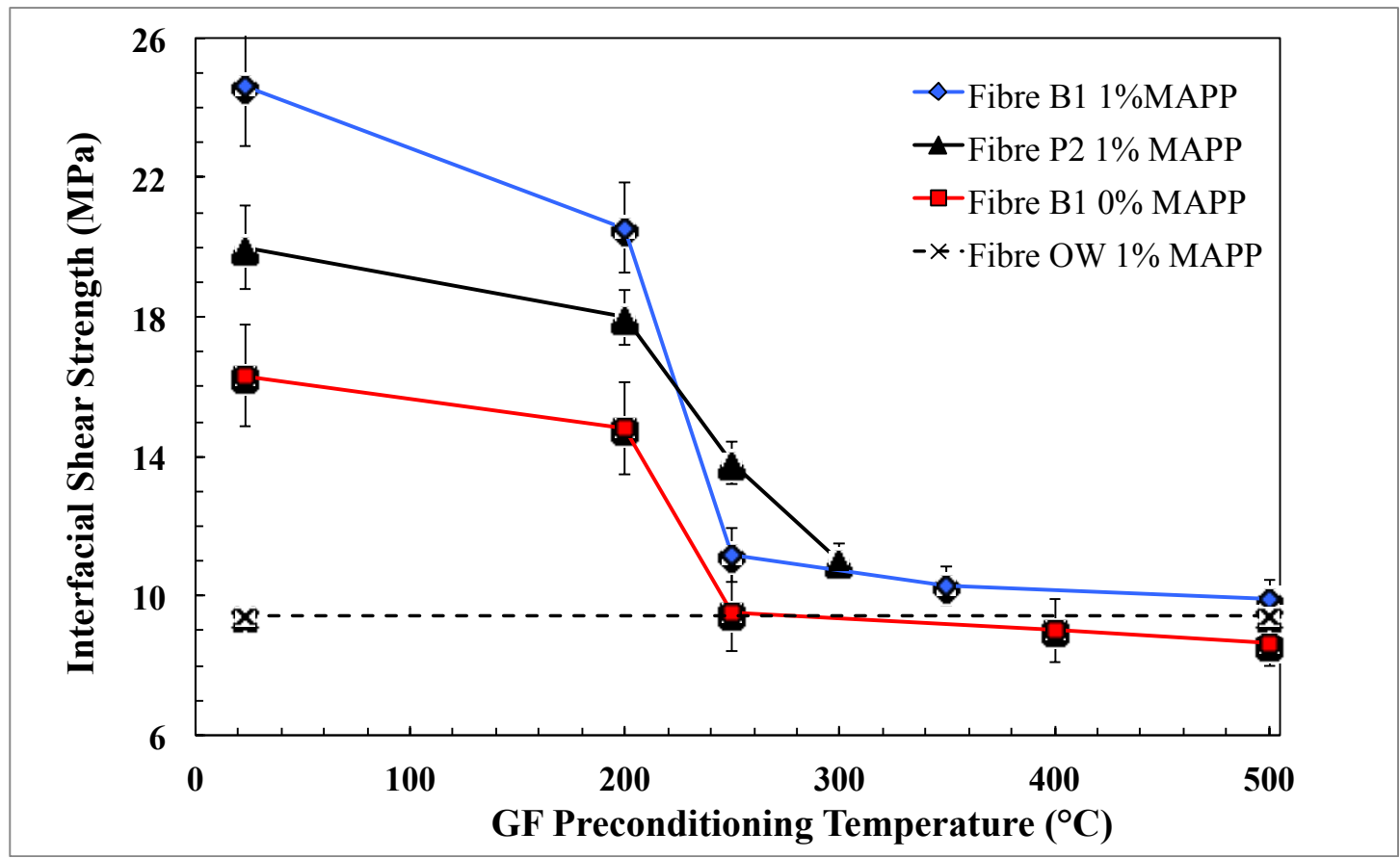

Figure 9 Effect of fibre preconditioning temperature on IFSS performance in MAPP

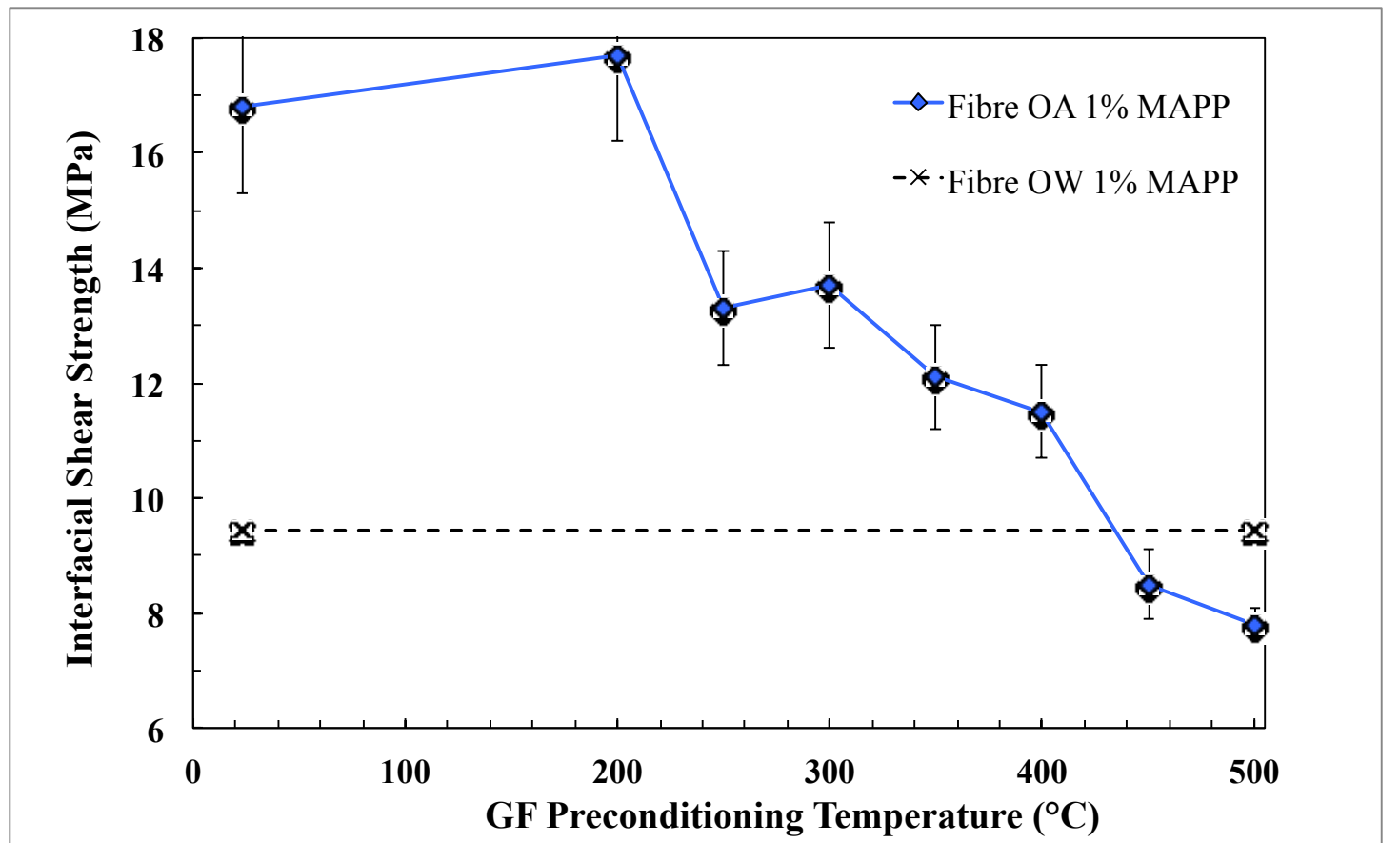

Figure 10 Effect of fibre preconditioning temperature on IFSS performance of APS sized fibre OA and water sized fibre OW in MAPP 


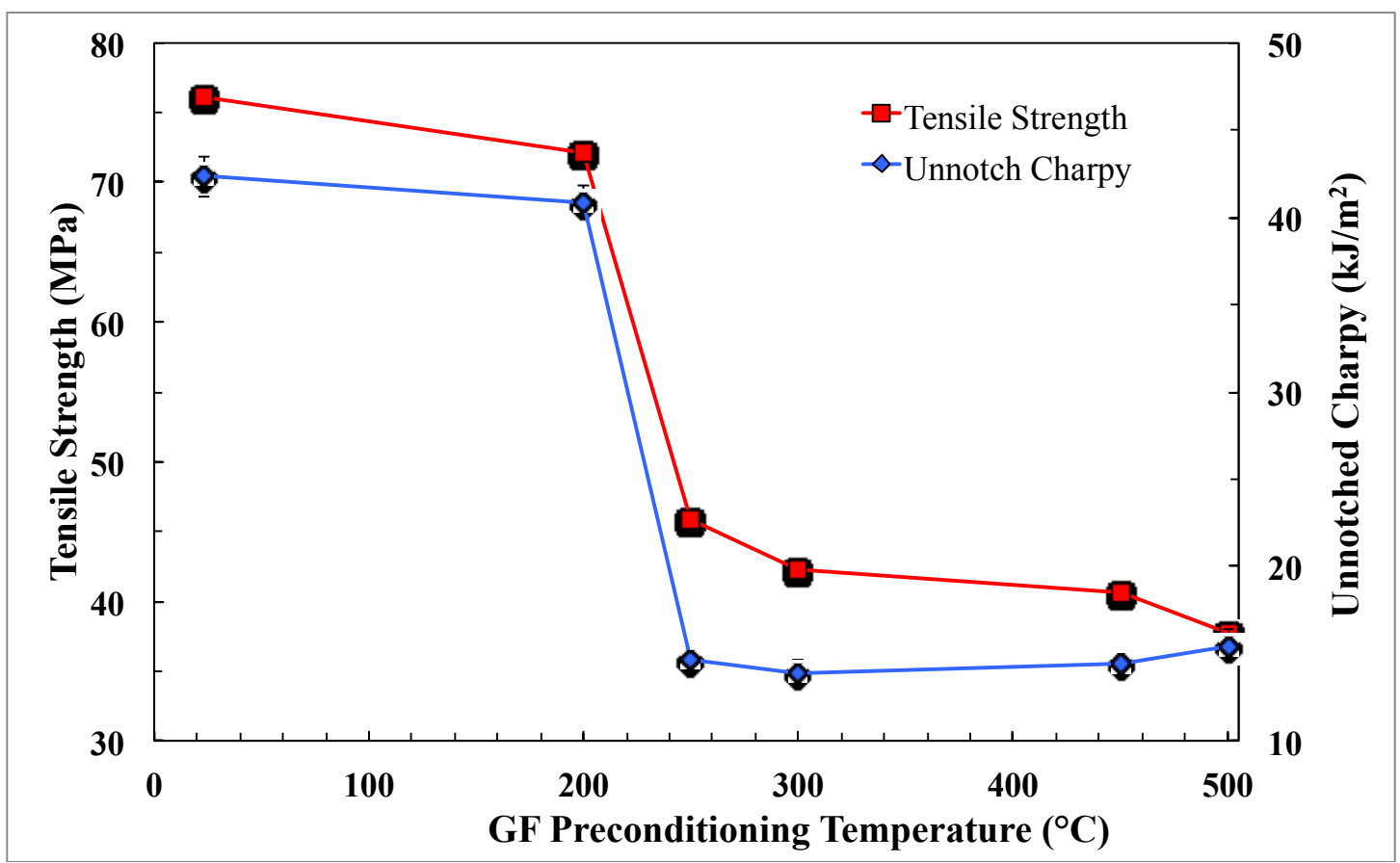

Figure 11 Effect of fibre preconditioning temperature on performance of $30 \%$ GF-PP composites

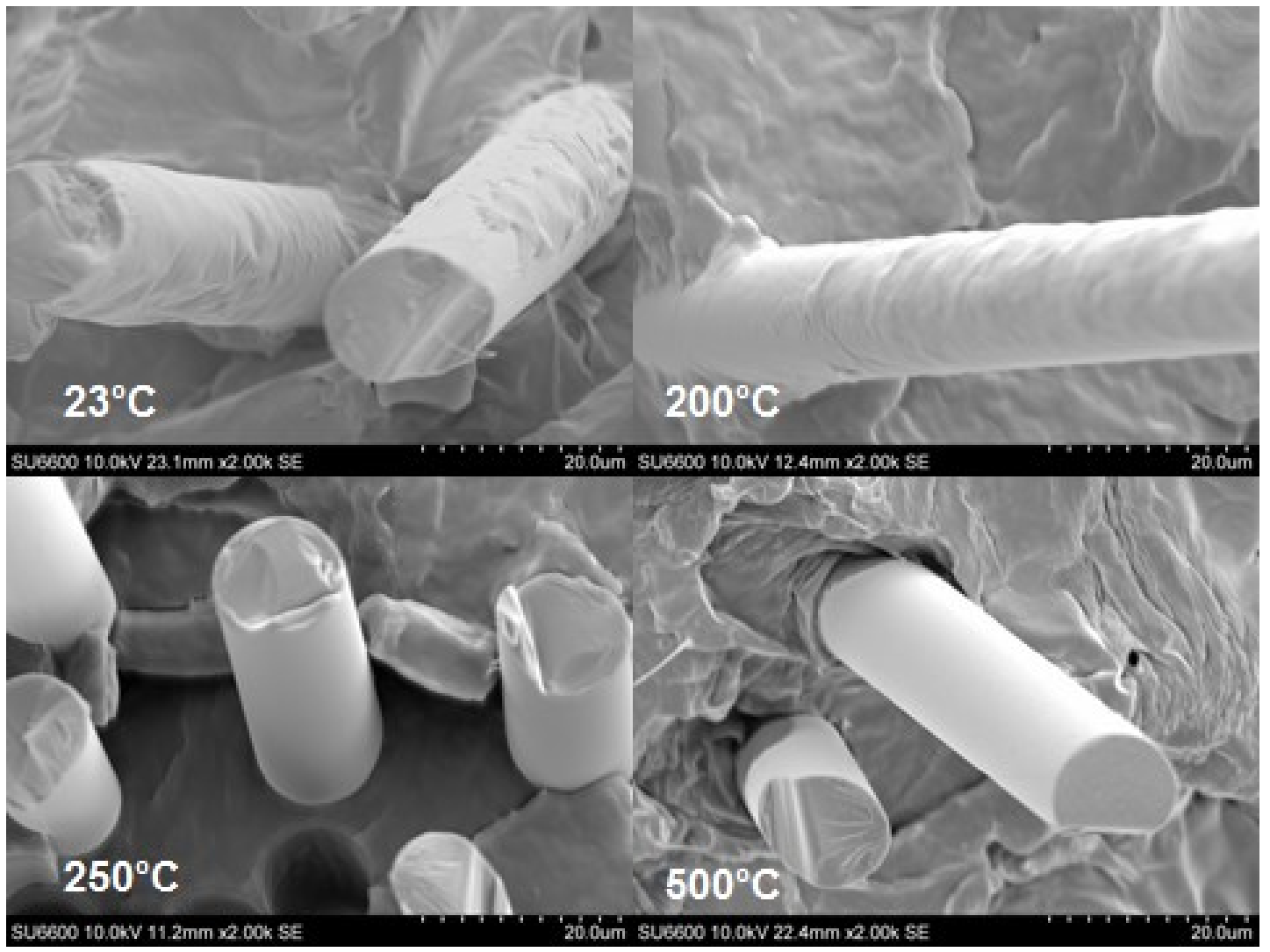

Figure 12 SEM micrographs of composites made with fibres preconditioned at different temperatures 


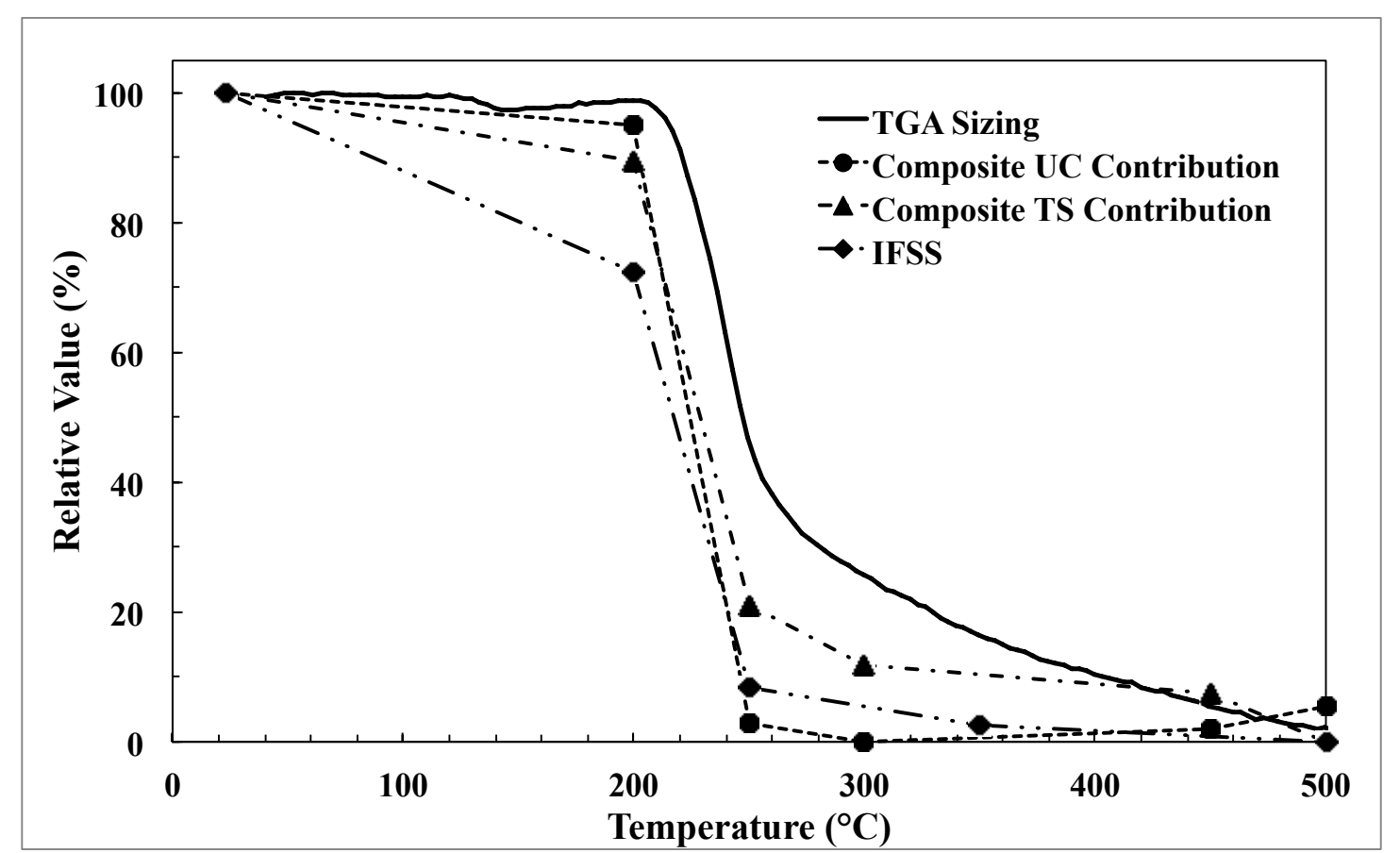

Figure 13 Comparison of the TGA mass loss in air of the sizing on Fibre B1 with the effect of thermal pretreatment of fibres on IFSS and composite performance 